\title{
Desempenho de frangos de corte alimentados com rações contendo diferentes níveis de cálcio suplementadas com fitase ${ }^{1}$
}

\author{
Daniella Carolina Zanardo Donato ${ }^{2}$, Ricardo de Albuquerque ${ }^{2}$, Paula Duarte Silva Rangel \\ Garcia $^{2}$, Júlio César de Carvalho Balieiro ${ }^{3}$
}

\footnotetext{
1 Pesquisa financiada pela FAPESP.

2 Departamento de Nutrição e Produção Animal - FMVZ/USP.

${ }^{3}$ Departamento de Ciências Básicas - FZEA/USP.
}

RESUMO - Um experimento foi conduzido para avaliar o efeito de rações contendo diferentes níveis de cálcio e suplementadas com fitase sobre o desempenho de frangos de corte nas fases inicial (1 a 21 dias), de crescimento (22 a 35 dias) e final (36 a 42 dias). Foram utilizados 2.160 pintos de corte machos da linhagem AG Ross 308, de 1 a 42 dias de idade, distribuídos em 6 tratamentos, cada um com 6 repetições. Foi utilizado um delineamento inteiramente casualizado em esquema fatorial $3 \times 2$, com 3 níveis de fitase $(0,600$ e $1.200 \mathrm{ftu} / \mathrm{kg})$ e 2 de cálcio $(0,94$ e 0,66\%; 0,84 e 0,59\%; e 0,78 e 0,54\% para as fases inicial, de crescimento e final, respectivamente). As rações experimentais ainda tinham níveis reduzidos de fósforo disponível e níveis mínimos de proteína bruta. Ao final de cada fase, avaliaram-se o ganho de peso, o consumo de ração, a conversão alimentar e a mortalidade. Houve interação entre os níveis de fitase e de cálcio estudados para ganho de peso, consumo de ração e mortalidade nas três fases avaliadas. Os melhores resultados foram obtidos com a suplementação de fitase no nível de $1.200 \mathrm{ftu} / \mathrm{kg}$ de ração em associação aos menores níveis de cálcio. Nenhum resultado significativo foi observado para conversão alimentar. Os níveis nutricionais de cálcio podem ser reduzidos em 30\% em dietas com baixos níveis de fósforo disponível e níveis mínimos de proteína bruta, desde que as dietas sejam suplementadas com $1.200 \mathrm{ftu} / \mathrm{kg}$ de fitase.

Palavras-chave: avicultura, enzima, fósforo disponível

\section{Performance of broilers fed diets with different calcium levels and supplemented with phytase}

\begin{abstract}
An experiment was carried out to evaluate the effect of diets with different calcium levels and supplemented with phytase on the performance of broiler chickens in initial (1 to 21 days of age), growing (22 to 35 days of age) and final (36 to 42 days of age) phases. Two thousand one hundred and sixty male broilers from AG Ross 308 line, from 1 to 42 days old were distributed in 6 treatments, with 6 replicates each. A completely randomized design in a $3 \times 2$ factorial scheme was used, with 3 phytase levels $(0,600$ or $1,200 \mathrm{ftu} / \mathrm{kg})$ and 2 calcium levels $(0.94 \%$ and $0.66 \%$; $0.84 \%$ and $0.59 \%$; and $0.78 \%$ and $0.54 \%$ to initial, growing and final phases, respectively). The experimental diets had lower available phosphorus levels and minimum crude protein levels. At the end of each phase the weight gain, feed intake, feed conversion and death rate were evaluated. There was significant interaction between phytase and calcium levels for weight gain, feed intake and death rate in all studied phases, with best results observed for treatments constituted by 1,200 ftu/kg of phytase and lower calcium levels on the diets. No significant results were observed to FC. Nutritional calcium levels can be reduced in $30 \%$, in diets with lower available phosphorus and minimum crude protein levels, since the diet is supplemented 1,200 ftu/kg of phytase.
\end{abstract}

Key Words: available phosphorus, enzyme, poultry

\section{Introdução}

Muitos estudos têm sido realizados para determinar as exigências nutricionais das aves, visando obter uma alimentação que proporcione máximo desempenho e que tenha menor custo. Entre os minerais exigidos pelas aves, o fósforo e o cálcio são os mais importantes, por serem necessários não apenas para a ótima taxa de desempenho, mas também para a mineralização óssea (Gomes, 2004). O fósforo também se destaca pela sua participação em inúmeras funções do organismo animal e pelo seu elevado custo na suplementação nas rações das aves.

A alimentação de aves baseia-se em ingredientes de origem vegetal, em especial o milho e o farelo de soja, que apresentam parte do teor de fósforo na forma do complexo orgânico fitato, cujo fósforo somente é aproveitado pelas 
aves em pequena proporção do total presente no alimento (aproximadamente 33\%). O fitato pode, então, ser considerado um fator antinutricional, já que diminui significativamente a disponibilidade de fósforo, formando também complexos insolúveis que prejudicam a digestibilidade dos nutrientes (Costa et al., 2004) e consequentemente o desempenho dos animais.

Em revisão, Choct (2006) destacou que a fitase exógena permite aumentar entre 25 a 50-70\% a disponibilidade do fósforo proveniente do fitato. Em trabalhos recentes, verifica-se que é possível reduzir níveis de nutrientes nas rações, mantendo satisfatoriamente o desempenho das aves e minimizando a excreção de alguns elementos minerais (Gomide et al., 2007; Silva et al., 2008).

Tanto o nível de cálcio quanto o de fósforo na ração para frangos influenciam a utilização do fósforo fítico (Schoulten, 2002). Aves consumindo rações com baixos níveis de fósforo e cálcio inorgânicos possuem maior capacidade para hidrolisar o fitato do que aquelas que recebem níveis altos (Denbow et al., 1995).

Assim, este trabalho foi conduzido para avaliar o desempenho de frangos de corte alimentados com rações contendo diferentes níveis de cálcio e suplementadas com fitase, considerando o efeito das fases acumuladas, nas fases inicial ( 1 a 21 dias), de crescimento (1 a 35 dias) e final (1 a 42 dias).

\section{Material e Métodos}

O experimento foi conduzido no aviário experimental do Departamento de Nutrição e Produção Animal da Faculdade de Medicina Veterinária e Zootecnia da Universidade de São Paulo, Campus Pirassununga, estado de São Paulo.

Foram utilizados 2.160 pintos de corte, com um dia de idade, machos, da linhagem AG Ross 308, criados até 42 dias de idade, sendo que no primeiro dia do experimento eles foram pesados, uniformizados e distribuídos, aleatoriamente, em um galpão de alvenaria, dividido em 36 boxes (1,70 $\mathrm{m} \times$ $2,50 \mathrm{~m}$ ), com piso forrado com maravalha e providos de comedouros tubulares e bebedouros pendulares, e submetidos aos tratamentos experimentais. Aos 21, 35 e 42 dias de idade avaliou-se o ganho de peso (GP), o consumo de ração (CR), a conversão alimentar (CA) e a mortalidade (Mort) no período experimental.

O delineamento experimental adotado foi o inteiramente casualizado, com os tratamentos organizados de acordo com um esquema fatorial $3 \times 2$, para cada uma das três fases (inicial, crescimento e terminação), sendo 3 níveis de enzima fitase (Natuphos $\left.{ }^{\circledR}\right)(0,600$ e $1200 \mathrm{ftu} / \mathrm{kg})$ e 2 níveis de Ca $(0,94$ e $0,66 \%$; 0,84 e $0,59 \% ; 0,78$ e $0,54 \%$, para as fases inicial, de crescimento e terminação, respectivamente), totalizando 6 tratamentos, com 6 repetições cada.

As rações foram isonutritivas (Tabelas 1, 2 e 3), exceto para os níveis de Ca, e foram formuladas à base de milho e farelo de soja, obedecendo aos níveis nutricionais empregados na criação comercial de frangos de corte. Em todas as rações foram utilizados níveis mínimos de proteína bruta (PB) e níveis reduzidos em 30\% de fósforo disponível para as diferentes fases $(0,27 ; 0,22$ e $0,20 \%$, para as fases inicial, de crescimento e final, respectivamente). Para os demais nutrientes foram atendidos os níveis recomendados para criação comercial. Os níveis de cálcio e fitase nas rações foram ajustados por redução/aumento do calcário e da enzima fitase e as respectivas substituições por inerte.

As análises estatísticas foram realizadas pelo pacote computacional SAS (2004). Foram analisados os efeitos do cálcio, da fitase, bem como a interação entre o cálcio e a fitase (Ca*Fitase), essas análises foram realizadas através de contrastes pelo PROC GLM SAS (2004).

Foi realizada também uma análise de regressão para os três níveis de fitase e a interação entre o cálcio e a fitase (Ca*Fitase), através do PROC REG SAS (2004).

Todos os dados obtidos foram submetidos ao teste de variância, através do SAS (2004), adotando-se nível de significância de $5 \%$.

\section{Resultados e Discussão}

Foram observadas interações quadráticas entre os níveis de fitase e de cálcio avaliados para ganho de peso, consumo de ração e a taxa de mortalidade para as três fases estudadas (Tabelas 4, 6 e 8), no entanto apenas equações lineares foram significativas (Tabelas 5, 7 e 9). Nenhum resultado significativo foi observado para a conversão alimentar.

Para o ganho de peso, nas três fases estudadas, as equações obtidas foram lineares crescentes (Tabelas 5 , 7 e 9), tanto para os níveis de cálcio mais altos, quanto para os mais baixos, indicando, nos dois casos, que quanto maior o nível de fitase na dieta, maior o ganho de peso. Todavia, maiores resultados de ganho de peso (Tabelas 4 , 6 e 8) foram observados quando os níveis de cálcio na dieta eram os menores $(0,66 \%, 0,59 \%$ e $0,54 \%$ para as fases inicial, de crescimento e terminação, respectivamente), sugerindo que o ajuste da relação Ca:P para 2:1 favoreceu o melhor ganho de peso.

Esses resultados são semelhantes aos encontrados por Qian et al. (1997), os quais encontraram que o ganho de peso aumentou com o acréscimo do nível de fitase da dieta e também com a diminuição da relação Ca:P. Costa et al. (2007) 
Tabela 1 - Composição percentual e nutritiva das rações experimentais (fase inicial)

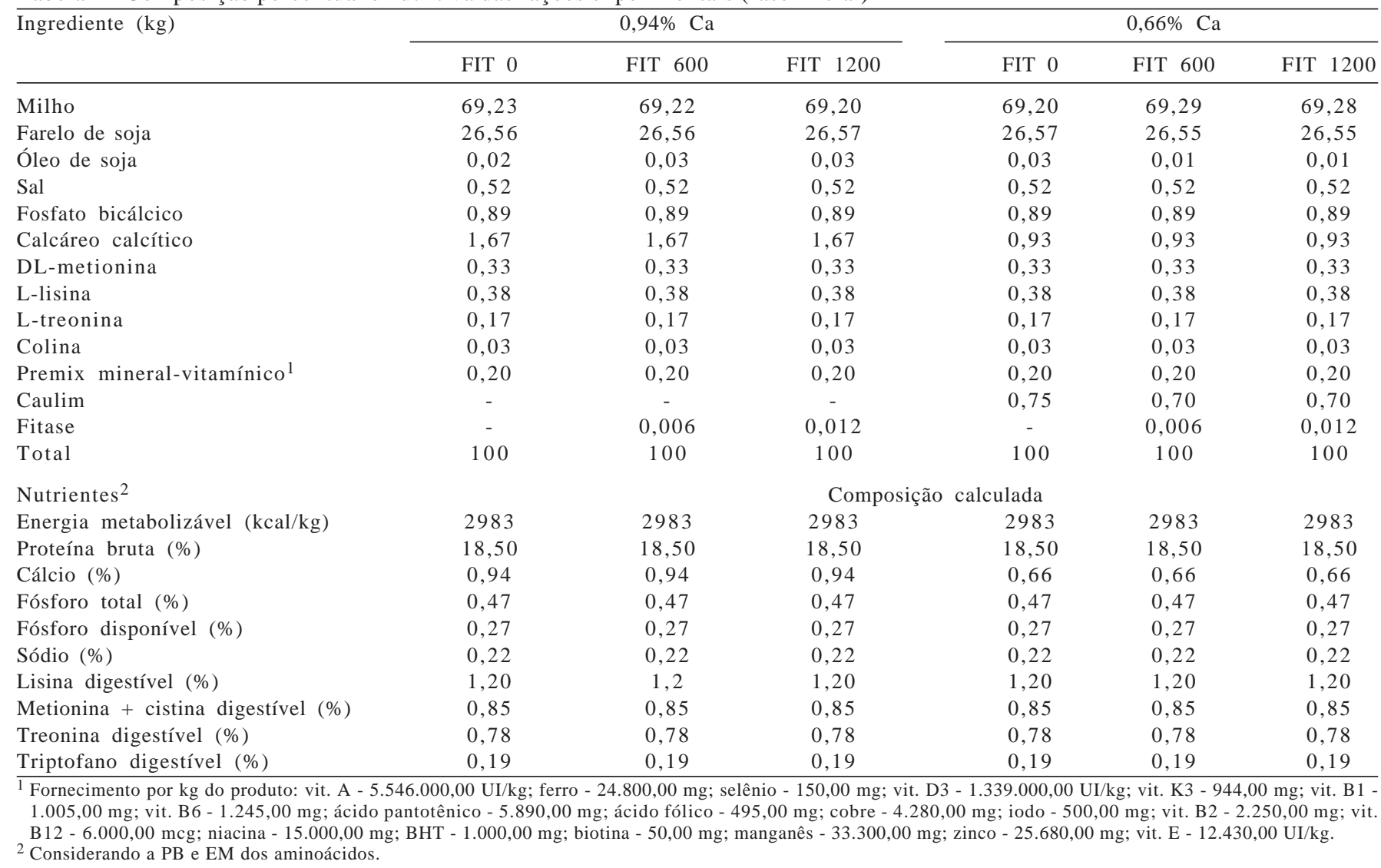

Tabela 2 - Composição percentual e nutritiva das rações experimentais (fase de crescimento)

\begin{tabular}{|c|c|c|c|c|c|c|}
\hline \multirow[t]{2}{*}{ Ingrediente (kg) } & \multicolumn{3}{|c|}{$0,84 \% \mathrm{Ca}$} & \multicolumn{3}{|c|}{$0,59 \% \mathrm{Ca}$} \\
\hline & FIT 0 & FIT 600 & FIT 1200 & FIT 0 & FIT 600 & FIT 1200 \\
\hline Milho & 70,22 & 70,21 & 70,20 & 70,24 & 70,23 & 70,21 \\
\hline Óleo de soja & 1,62 & 1,63 & 1,63 & 1,62 & 1,63 & 1,63 \\
\hline Sal & 0,48 & 0,48 & 0,48 & 0,48 & 0,48 & 0,48 \\
\hline Fosfato bicálcico & 0,65 & 0,65 & 0,65 & 0,65 & 0,65 & 0,65 \\
\hline L-lisina & 0,30 & 0,30 & 0,30 & 0,30 & 0,30 & 0,30 \\
\hline L-treonina & 0,12 & 0,12 & 0,12 & 0,12 & 0,12 & 0,12 \\
\hline Colina & 0,03 & 0,03 & 0,03 & 0,03 & 0,03 & 0,03 \\
\hline Premix mineral vitamínico ${ }^{1}$ & 0,20 & 0,20 & 0,20 & 0,20 & 0,20 & 0,20 \\
\hline Caulim & - & - & - & 0,65 & 0,65 & 0,65 \\
\hline Fitase & - & 0,006 & 0,012 & - & 0,006 & 0,012 \\
\hline Cálcio (\%) & 0,84 & 0,84 & 0,84 & 0,59 & 0,59 & 0,59 \\
\hline Fósforo total (\%) & 0,42 & 0,42 & 0,42 & 0,42 & 0,42 & 0,42 \\
\hline Fósforo disponível (\%) & 0,22 & 0,22 & 0,22 & 0,22 & 0,22 & 0,22 \\
\hline Sódio (\%) & 0,21 & 0,21 & 0,21 & 0,21 & 0,21 & 0,21 \\
\hline Lisina digestível (\%) & 1,07 & 1,07 & 1,07 & 1,07 & 1,07 & 1,07 \\
\hline Metionina + cistina digestível (\%) & 0,77 & 0,77 & 0,77 & 0,77 & 0,77 & 0,77 \\
\hline Treonina digestível (\%) & 0,70 & 0,70 & 0,70 & 0,70 & 0,70 & 0,70 \\
\hline Triptofano digestível (\%) & 0,18 & 0,18 & 0,18 & 0,18 & 0,18 & 0,18 \\
\hline
\end{tabular}


Tabela 3 - Composição percentual e nutritiva das rações experimentais (fase final)

\begin{tabular}{|c|c|c|c|c|c|c|}
\hline \multirow[t]{2}{*}{ Ingrediente (kg) } & \multicolumn{3}{|c|}{$0,78 \%$ Са } & \multicolumn{3}{|c|}{$0,54 \% \mathrm{Ca}$} \\
\hline & FIT 0 & FIT 600 & FIT 1200 & FIT 0 & FIT 600 & FIT 1200 \\
\hline Milho & 73,75 & 73,75 & 73,74 & 73,76 & 73,75 & 73,74 \\
\hline Óleo de soja & 2,42 & 2,42 & 2,42 & 2,42 & 2,42 & 2,42 \\
\hline Sal & 0,45 & 0,45 & 0,45 & 0,45 & 0,45 & 0,45 \\
\hline Fosfato bicálcico & 0,55 & 0,55 & 0,55 & 0,55 & 0,55 & 0,55 \\
\hline L-lisina & 0,38 & 0,38 & 0,38 & 0,38 & 0,38 & 0,38 \\
\hline L-treonina & 0,16 & 0,16 & 0,16 & 0,16 & 0,16 & 0,16 \\
\hline L-triptofano & 0,02 & 0,02 & 0,02 & 0,02 & 0,02 & 0,02 \\
\hline Colina & 0,03 & 0,03 & 0,03 & 0,03 & 0,03 & 0,03 \\
\hline Premix mineral vitamínico ${ }^{1}$ & 0,20 & 0,20 & 0,20 & 0,20 & 0,20 & 0,20 \\
\hline Caulima & - & - & - & 0,60 & 0,60 & 0,60 \\
\hline Proteína bruta (\%) & 16,00 & 16,00 & 16,00 & 16,00 & 16,00 & 16,00 \\
\hline Cálcio (\%) & 0,78 & 0,78 & 0,78 & 0,54 & 0,54 & 0,54 \\
\hline Fósforo total (\%) & 0,39 & 0,39 & 0,39 & 0,39 & 0,39 & 0,39 \\
\hline Fósforo disponível (\%) & 0,20 & 0,20 & 0,20 & 0,20 & 0,20 & 0,20 \\
\hline Sódio (\%) & 0,20 & 0,20 & 0,20 & 0,20 & 0,20 & 0,20 \\
\hline Lisina digestível (\%) & 1,05 & 1,05 & 1,05 & 1,05 & 1,05 & 1,05 \\
\hline Metionina + cistina digestível (\%) & 0,76 & 0,76 & 0,76 & 0,76 & 0,76 & 0,76 \\
\hline Treonina digestível (\%) & 0,68 & 0,68 & 0,68 & 0,68 & 0,68 & 0,68 \\
\hline Triptofano digestível (\%) & 0,18 & 0,18 & 0,18 & 0,18 & 0,18 & 0,18 \\
\hline
\end{tabular}

Tabela 4 - Ganho de peso, consumo de ração, conversão alimentar e mortalidade por frangos de corte de 1 a 21 dias de idade segundo níveis de fitase e cálcio na dieta

\begin{tabular}{|c|c|c|c|c|c|c|c|c|c|c|c|c|c|}
\hline & \multicolumn{6}{|c|}{ Dieta experimental } & \multirow[t]{3}{*}{ Média } & \multirow[t]{3}{*}{$\mathrm{CV}$} & \multirow[t]{3}{*}{$\mathrm{Ca}$} & \multicolumn{4}{|c|}{ Valor de $\mathrm{P}$} \\
\hline & \multicolumn{3}{|c|}{ 0,94\% Сa } & \multicolumn{3}{|c|}{ 0,66\% Ca } & & & & \multicolumn{2}{|c|}{ Fitase } & \multicolumn{2}{|c|}{ Ca* Fitase } \\
\hline & Fit 0 & Fit 600 & Fit 1200 & Fit 0 & Fit 600 & Fit 1200 & & & & $\mathrm{~L}$ & Q & $\mathrm{L}$ & Q \\
\hline Ganho de peso (g) & 0,544 & 0,729 & 0,764 & 0,721 & 0,799 & 0,827 & 0,731 & 2,44 & $<0,001$ & $<0,001$ & $<0,001$ & 0,006 & $<0,001 *$ \\
\hline Consumo de ração (g) & 0,898 & 1,161 & 1,273 & 1,156 & 1,240 & 1,274 & 1,167 & 11,50 & 0,004 & 0,084 & 0,015 & 0,801 & $0,007 *$ \\
\hline Conversão alimentar (g/g) & 1,649 & 1,592 & 1,667 & 1,603 & 1,551 & 1,541 & 1,601 & 10,83 & 0,987 & 0,874 & 0,892 & 0,377 & 0,201 \\
\hline Mortalidade (\%) & 15,894 & 3,889 & 1,944 & 3,333 & 1,111 & 0,556 & 9,454 & 18,37 & $<0,001$ & 0,006 & $<0,001$ & 0,846 & $<0,001 *$ \\
\hline
\end{tabular}

* $\mathrm{P}<0,01$.

Tabela 5 - Equações de regressão para as variáveis ganho de peso, consumo de ração e mortalidade para frangos de corte de 01 a 21 dias de idade

\begin{tabular}{llr}
\hline & Equação de regressão & $\mathrm{R}^{2}$ \\
\hline Ganho de peso $(0,94 \% \mathrm{Ca})$ & $\mathrm{Y}=0,5693+0,00018 \mathrm{X}$ & $<0,001$ \\
Ganho de peso $(0,66 \% \mathrm{Ca})$ & $\mathrm{Y}=0,7297+0,000088 \mathrm{P}$ & $<0,001$ \\
Consumo de ração $(0,94 \% \mathrm{Ca})$ & $\mathrm{Y}=0,9238+0,00031 \mathrm{X}$ & $<0,001$ \\
Mortalidade $(0,94 \% \mathrm{Ca})$ & $\mathrm{Y}=19,2175-0,0116 \mathrm{X}$ & $<0,001$ \\
Mortalidade $(0,66 \% \mathrm{Ca})$ & $\mathrm{Y}=8,0556-0,0023 \mathrm{X}$ & 0,61 \\
\hline
\end{tabular}

observaram aumento no ganho de peso para aves que consumiram a dieta suplementada com a enzima. Esses autores ainda sugerem que este aumento no ganho de peso dos animais pode ter ocorrido pela diminuição da viscosidade intestinal das aves, melhorando a digestão e absorção dos nutrientes no trato digestivo destes animais.

Para o consumo de ração, também foram significativas apenas equações lineares crescentes (Tabelas 5, 7 e 9), exceto para os níveis de $0,66 \%$ e $0,59 \%$ de cálcio (das 
Tabela 6 - Ganho de peso, consumo de ração, conversão alimentar e mortalidade por frangos de corte de 1 a 35 dias de idade segundo níveis de fitase e cálcio na dieta

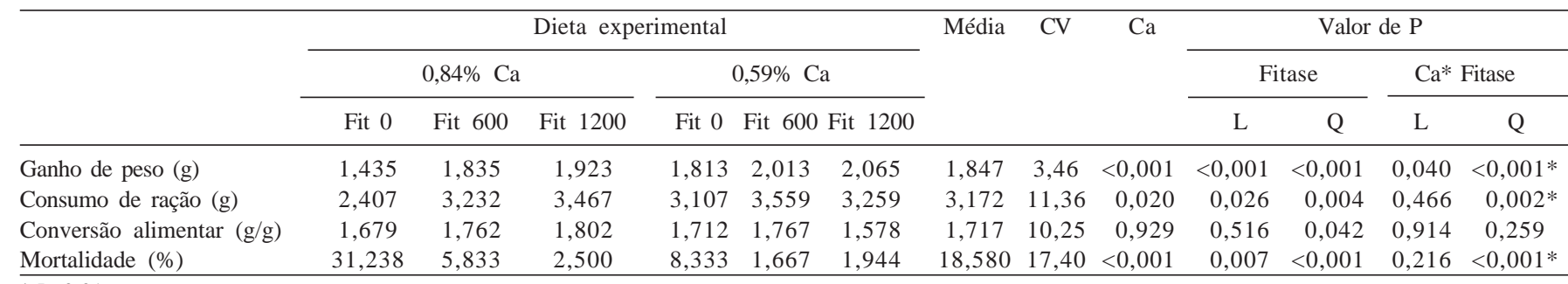

* $\mathrm{P}<0,01$.

Tabela 7 - Equações de regressão para ganho de peso, consumo de ração e mortalidade para frangos de corte de 1 a 35 dias de idade

\begin{tabular}{lccc}
\hline & Equação de regressão & Valor de $\mathrm{P}$ & \multicolumn{1}{c}{$\mathrm{R}^{2}$} \\
\hline Ganho de peso $(0,84 \% \mathrm{Ca})$ & $\mathrm{Y}=1,4871+0,00040 \mathrm{X}$ & $<0,001$ & $<0,001$ \\
Ganho de peso $(0,59 \% \mathrm{Ca})$ & $\mathrm{Y}=1,8383+0,00021 \mathrm{X}$ & $<0,001$ & 0,79 \\
Consumo de ração $(0,84 \% \mathrm{Ca})$ & $\mathrm{Y}=2,5060+0,00088 \mathrm{X}$ & $<0,001$ & 0,82 \\
Mortalidade $(0,84 \% \mathrm{Ca})$ & $\mathrm{Y}=38,2540-0,0246 \mathrm{X}$ & 0,006 & 0,77 \\
Mortalidade $(0,59 \% \mathrm{Ca})$ & $\mathrm{Y}=17,3148-0,0060 \mathrm{X}$ & 0,53 \\
\hline
\end{tabular}

Tabela 8 - Ganho de peso, consumo de ração, conversão alimentar e mortalidade por frangos de corte de 1 a 42 dias de idade segundo níveis de fitase e cálcio na dieta

\begin{tabular}{|c|c|c|c|c|c|c|c|c|c|c|c|c|c|}
\hline & \multicolumn{6}{|c|}{ Dieta experimental } & \multirow[t]{3}{*}{ Média } & \multirow[t]{3}{*}{ CV } & \multirow[t]{3}{*}{$\mathrm{Ca}$} & \multicolumn{4}{|c|}{ Valor de P } \\
\hline & \multicolumn{3}{|c|}{ 0,78\% Сa } & \multicolumn{3}{|c|}{ 0,54\% Ca } & & & & \multicolumn{2}{|c|}{ Fitase } & \multicolumn{2}{|c|}{$\mathrm{Ca}^{*}$ Fitase } \\
\hline & Fit 0 & Fit 600 & Fit 1200 & Fit 0 & Fit 600 & Fit 1200 & & & & $\mathrm{~L}$ & Q & $\mathrm{L}$ & Q \\
\hline Consumo de ração (g) & 3,439 & 4,457 & 4,760 & 4,359 & 4,883 & 5,008 & 4,484 & 5,05 & $<0,001$ & 0,001 & $<0,001$ & 0,241 & $<0,001^{*}$ \\
\hline Conversão alimentar (g/g) & 1,826 & 1,856 & 1,888 & 1,847 & 1,927 & 1,910 & 1,870 & 4,91 & 0,561 & 0,145 & 0,729 & 0,539 & 0,140 \\
\hline Mortalidade (\%) & 38,484 & 7,778 & 4,444 & 10,000 & 2,778 & 2,778 & 26,043 & 11,56 & $<0,001$ & 0,002 & $<0,001$ & 0,124 & $<0,001^{*}$ \\
\hline
\end{tabular}

$* \mathrm{P}<0,01$.

Tabela 9 - Equações de regressão para as variáveis ganho de peso, consumo de ração e mortalidade para frangos de corte de 1 a 42 dias de idade

\begin{tabular}{lrrr}
\hline & Equação de regressão & Valor de P & $\mathrm{R}^{2}$ \\
\hline Ganho de peso $(0,78 \% \mathrm{Ca})$ & $\mathrm{Y}=1,9516+0,00053 \mathrm{X}$ & $<0,001$ & $<, 001$ \\
Ganho de peso $(0,54 \% \mathrm{Ca})$ & $\mathrm{Y}=2,3725+0,00022 \mathrm{X}$ & $<0,001$ & 0,76 \\
Consumo de ração $(0,78 \% \mathrm{Ca})$ & $\mathrm{Y}=3,5584+0,0011 \mathrm{X}$ & 0,005 & 0,81 \\
Consumo de ração $(0,54 \% \mathrm{Ca})$ & $\mathrm{Y}=4,4257+0,00054 \mathrm{X}$ & $<0,001$ & 0,54 \\
Mortalidade $(0,78 \% \mathrm{Ca})$ & $\mathrm{Y}=49,6160-0,0290 \mathrm{X}$ & 0,008 & 0,79 \\
Mortalidade $(0,54 \% \mathrm{Ca})$ & $\mathrm{Y}=23,9351-0,0067 \mathrm{X}$ & 0,51 \\
\hline
\end{tabular}

fases inicial e de crescimento, respectivamente), em que não foi obtida nenhuma equação significativa, uma vez que os resultados não apresentaram padrão de comportamento definido.

O consumo de ração aumentou com o acréscimo da inclusão de fitase na dieta e foi maior nos menores níveis de cálcio da dieta (Tabelas 4, 6 e 8). Com isso pode-se inferir que a alta relação Ca:P, encontrada nas dietas sem fitase ou com adição de 600 ftu, e principalmente naquelas com maiores níveis de cálcio, limitou o consumo de ração das aves. Kies et al. (2001) também afirmaram que baixos níveis de fósforo disponível na dieta são fatores limitantes do consumo de ração pelas aves.

Em todas as fases estudadas também foram observados os mesmos padrões de resposta da taxa de mortalidade, a qual apresentou resposta linear decrescente (Tabelas 5, 7 e 9), e 
isso indica que, quanto mais ajustada para 2:1 a relação Ca:P, menor a mortalidade.

As maiores taxas de mortalidade foram observadas na ausência de fitase e maior nível de cálcio para as três idades (Tabelas 4, 6 e 8). Essa resposta se deve à ausência da enzima para aumentar a disponibilidade de fósforo e cálcio e, consequentemente, à alta relação cálcio:fósforo decorrente disso.

\section{Conclusões}

Para as três fases estudadas, os níveis nutricionais de cálcio podem ser reduzidos em $30 \%$, em dietas com níveis reduzidos de fósforo disponível e níveis mínimos de proteína bruta. Essa redução não afeta o desempenho, desde que as dietas sejam adicionadas de $1.200 \mathrm{ftu} / \mathrm{kg}$ de fitase.

\section{Agradecimentos}

À Basf, pelo fornecimento da enzima fitase Natuphos ${ }^{\circledR}$, e à Tortuga, pelo fornecimento do premix vitamínicomineral.

\section{Referências}

CHOCT, M. Enzymes for the feed industry: past, present and future. World's Poultry Science Journal, v.62, n.1, p.5-15, 2006. COSTA, F.G.P.; BRANDÃO, P.A.; BRANDÃO, J.S. et al. Efeito da enzima fitase nas rações de frangos de corte, durante as fases pré-inicial e inicial. Ciência e Agrotecnologia, v.31, n.3, p.865-870, 2007.

COSTA, F.G.P.; JÁCOME, I.M.T.D.; SILVA, J.H.V. et al. Níveis de fósforo disponível e de fitase na dieta de poedeiras de ovos de casca marrom. Ciência Animal Brasileira, v.5, n.2, p.73-81, 2004.

DENBOW, D.M.; RAVINDRAN, V.; KORNEGAY, E.T. et al. Improving phosphorus availability in soybean meal for broilers by supplemental phytase. Poultry Science, v.74, n.11, p.1831-1842, 1995.

GOMES, P.C.; RUNHO, R.C.; D’AGOSTINI, P. et al. Exigência de fósforo disponível para frangos de corte machos e fêmeas de 22 a 42 dias de idade. Revista Brasileira de Zootecnia, v.33, n.6, p.1734-1746, 2004 (supl. 1).

GOMIDE, E.M.; RODRIGUES, P.B. FREITAS, R.T.F. et al. Planos nutricionais com a utilização de aminoácidos e fitase para frangos de corte mantendo o conceito de proteína ideal nas dietas. Revista Brasileira de Zootecnia, v.36, n.6, p.1769-1774, 2007.

KIES, A.K.; VAN HEMERT, K.H.F.; SAUER, W.C. Effect of phytase on protein and amino acid digestibility and energy utilization. Wolrd's Poultry Science Journal, v.57, p.109-126, 2001.

QIAN, H.; KORNEGAY, E.T.; DENBOW, D.M. Utilization of phytate phosphorus and calcium as influenced by microbial phytase, cholecalciferol, and the calcium:total phosphorus ratio in broiler diets. Poultry Science, v.76 p.37-46, 1997.

ROSTAGNO, H.S.; ALBINO, L.F.T.; DONZELE, J.L. et al. Tabelas brasileiras para aves e suínos: composição de alimentos e exigências nutricionais. 2.ed. Viçosa, MG: UFV, 2005. 141p.

SCHOULTEN, N.A.; TEIXEIRA, A.S.; SILVA, H.O. et al. Efeito dos níveis de cálcio da ração suplementada com fitase sobre a absorção de minerais em frangos de corte de 22 a 42 dias. Ciência Animal Brasileira, v.3, n.1, p.31-37, 2002.

SILVA, Y.L.; RODRIGUES, P.B.; FREITAS, R.T.F. et al. Níveis de proteína e fósforo em rações com fitase para frangos de corte, na fase de 14 a 21 dias de idade. 2. Valores energéticos e digestibilidade de nutrientes. Revista Brasileira de Zootecnia, v.37, n.3, p.469-477, 2008.

STATISTICAL ANALYSIS SYSTEM - SAS. SAS users guide: statistics. Cary: 2004. (CD-ROM). 